\title{
Recreating Living Experiences from Past Memories through Virtual Worlds for People with Dementia
}

\author{
Panote Siriaraya \\ Faculty of Industrial Design \\ Engineering, Delft University of \\ Technology, Landbergstraat 152628 \\ CE Delft, The Netherlands
}

\author{
Chee Siang Ang \\ School of Engineering and Digital \\ Arts, University of Kent, CT2 7NT, \\ United Kingdom
}

\begin{abstract}
This paper describes a study aimed to understand the use of 3D virtual world (VW) technology to support life engagement for people with dementia in long-term care. Three versions of VW prototypes (reminiscence room, virtual tour and gardening) utilising gestured-base interaction were developed iteratively. These prototypes were tested with older residents $(80+)$ with dementia in care homes and their caregivers. Data collection was based on observations of how the residents and care staff interacted collaboratively with the VW. We discussed in depth the use of VWs in stimulating past memories and how this technology could help enhance their sense of self through various means. We also highlighted key approaches in designing VWs to sustain attention, create ludic experiences and facilitate interaction for older people with dementia.
\end{abstract}

\section{Author Keywords}

3D virtual worlds; older people; care home; dementia; gesture-based interaction

\section{ACM Classification Keywords}

H.5.m. Information interfaces and presentation (e.g., HCI): Miscellaneous.

\section{INTRODUCTION}

The care of dementia is becoming a key agenda in health care research. A report published by the Health Economics Research Centre estimated that the cost of dementia in care and lost productivity in the UK could be as high as £23 billion [26]. Another report estimated the cost of care in the US to be $\$ 203$ billion in 2013 [1]. Dementia not only affects those suffering from it but also incurs a personal cost to those taking care of them. Therefore, there is a strong interest in finding ways to assist the care of people with dementia. Increasingly, the CHI community is looking into ways to design technology to support specifically dementia care and more generally older people in care homes $[35,18,17]$. Virtual world (VW) technologies have

Permission to make digital or hard copies of all or part of this work for personal or classroom use is granted without fee provided that copies are not made or distributed for profit or commercial advantage and that copies bear this notice and the full citation on the first page. Copyrights for components of this work owned by others than ACM must be honored. Abstracting with credit is permitted. To copy otherwise, or republish, to post on servers or to redistribute to lists, requires prior specific permission and/or a fee. Request permissions from Permissions@acm.org.

CHI 2014, April 26 - May 01 2014, Toronto, ON, Canada

Copyright 2014 ACM 978-1-4503-2473-1/14/04 \$15.00.

http://dx.doi.org/10.1145/2556288.2557035 great potentials in enhancing dementia care. The high fidelity imagery generated in VW could create "living experiences", experiences which are interactive, engaging and immersive for people with dementia. Reliving past experiences could help stimulate memories, provide positive emotions and enhance their sense of self. In line with the recent work in dementia within the CHI community, the aim of this study is to understand how 3D VWs can be designed to support life engagement for people with dementia in long-term care. More specifically, the objectives of this study are to:

- investigate how older people with dementia engage with virtual worlds and how they relate their selfhood and identity to the various aspects of virtual worlds.

- examine how virtual worlds can be designed to encourage sustained ludic experiences with residents.

\section{Dementia and old age}

Various declines in the physical and cognitive abilities are almost inevitable as we enter old age, and this could result in deterioration of quality of life [33]. Dementia is an increasingly common condition related to the decline of cognitive abilities. Dementia is not a single disease, but a set of symptoms which include losses of cognitive functions, declines in memory, attention as well as impairments in reasoning and planning abilities [37]. In some cases, those with dementia are also found to undergo changes in their personality and behaviour [7]. Alzheimer's disease is a common cause of dementia, resulting in a progressive deterioration in cognitive abilities, memory and mood changes [28]. Due to this variability of dementia, providing good care for people with dementia is not easy. They often have difficulties in communication, making interaction very challenging. Apart from cognitive declines due to dementia, many of them have impaired abilities in various daily activities such as problems with eating, and high level of incontinence. To further exacerbate the situation, they do not usually have the verbal ability to complain about their care. If they try to communication via their behaviour, it is often treated as a symptom to be suppressed [27].

In recent years, dementia care has gradually adopted a person-centred approach based on social interaction [14]. One such approach is known as Intensive Interaction (II). 
Introduced by Ephraim [15], it is traditionally used with people with learning disabilities and autism. A main issue II aims to address is to promote social interaction for individuals with difficulty in communication. Caldwell, a practitioner and advocate of II, outlined some useful practical guides in [8]. The key technique involves using the client's own non-verbal body language to get in touch with them by understanding their noises, movements, gestures and rhythms. Virtual worlds are a way of helping patients use non-verbal body language to affect their environment that could complement traditional II and support reminiscence by transporting users back to familiar contexts

\section{Technology in dementia care}

Various technologies have been designed and proposed to assist the care of people with dementia. These include context-aware memory aids to provide useful reminders, and devices to help older people carry out everyday tasks such as hand washing (see a summary in [2]). A number of these technologies were targeted at residents in care homes. Examples include a photostroller device which displays a stream of pictures to provide ludic engagement [17] and a touch screen system to facilitate the creation of music [32]. Many of these devices were based on the idea of supporting reminiscence activities to a certain extent. Reminiscence therapy is described as an activity where older people are asked to recall memories of events and experience from their past. Often, visual and audio aids or other tangible artefacts such as photographs are used [39]. Such activities have been shown to improve cognitive functioning and morale [36]. Some technologies have been developed to facilitate reminiscence therapy. These include an interactive multimedia tool [18] and a networked system employing an IP videophone and a photo/video sharing system [23].

\section{Virtual worlds and their potential in dementia care}

One technology with potential benefits to people with dementia is the $3 \mathrm{D}$ virtual world (VW). The combination of interactivity and the ability to provide a high fidelity $3 \mathrm{D}$ visualisation of places and objects offers a unique experience for users that is difficult to achieve using traditional media. For instance, VWs could be used as aids in reminiscence activities, allowing users to interact with objects which are hard (or expensive) to obtain in the physical world (e.g. a retro car) or to provide an experience of a place which is no longer possible to access (such as a historic street from the past). The interactivity of the virtual environments could allow older people to not only be passive viewers of the objects and scenes, but also engage actively in a more playful and creative experience of reminiscence. There have been few studies looking into the use of VW technology in the care of older people with dementia in care homes. This technology has been used indirectly as visualisation tools to visualise the activities and locations of older people for caregivers and their family members [4]. It has also been used to provide relaxation to trigger positive emotions among older people [6] and to provide a representation of a place from the past (e.g. a bar) [18]. In this study, we examined in depth the idea of using VW to support life engagement for those with dementia in the long-term care. In this paper, we documented the key observations throughout our eight-month study, highlighting the design process and the relationship between selfhood and memories which emerged from their engagement with VW.

Our approach is different from previous work such as project CIRCA [18] in several ways. Firstly, we focus on creating a lively real time rendered 3D environment, instead of more "static" visualisation such as 360 Degree Panorama. This would potentially enhance the feeling of "presence", thus enhancing the benefit of use. Secondly, we make use of gesture-based technology (i.e. Kinect) to enhance the interaction and empower older people to interact with the system in a more natural manner. Thirdly, our design puts an emphasis on creating a virtual space for use in social interaction.

\section{METHOD}

Due to the difficulties in verbal communication for people with dementia, design studies involving older people with cognitive impairment are challenging [22]. Moreover, this user group tends to have little experience with technology. In order to overcome this, we used a mixed method in our study, involving observations, focus groups and interviews. Throughout the study, the virtual worlds design evolved iteratively based on the observations and feedback from the care staff. A series of facilitated sessions with different versions of the VW prototypes were carried out, during which the researchers observed and make detailed notes of the interaction and the personal conversation of residents and caregivers. A number of studies in care homes have also adopted similar approaches in their research $[17,18]$.

\section{Data collection \& Analysis}

The data collection was centred around the iterative development of a VW (see Table 1). A typical data collection session involved the carers (or activity facilitators) using the prototypes to engage the residents with virtual activities. The observation was carried out in a room designated for activity in the care homes. The groups ranged from five residents to sometimes just one resident. The residents were free to leave the room if they were no longer interested in the activity. The researchers were only there as external observers and to provide technical support. Detailed notes were taken during the observation. No voice or video recording devices were used due to ethical reasons. A total of 9 visits were made to 2 care homes and 8 observation sessions were carried out over the period of eight months, involving 6 carers/activities facilitators, 2 care home managers, and approximately 20 residents. After each visit where observation sessions were conducted, interviews were carried out with the care staff. The 
interviews were open-ended and involved discussing their opinions about the prototypes, suggesting ways to improve them and providing clarification on the observations. Additionally, two focus group sessions were carried out with the care staff and managers. The focus groups involved discussing the issues related to the prototypes design and identifying appropriate activity and content design (see table 1). The study was approved by the University Ethics Committee.

Data was analysed and categorised into themes using thematic analysis. The notes were read through by two researchers independently to gain an overall understanding. Patterns in the data were coded and the codes were refined into themes. Finally, to further refine and verify the themes, the two researchers critically discussed and reviewed each theme and underlying code together until they reached an agreement. Each theme highlights a key aspect of our observations on the recursive process used in the development of the prototypes and our interpretation of what was reflected when older people with dementia interacted with VWs.

\begin{tabular}{|c|c|c|}
\hline Visit & Home & Participants \\
\hline 1 & 1 & 2 managers (initial discussion) \\
\hline 2 & 1 & $\begin{array}{l}1 \text { staff, } 1 \text { volunteer, } 4 \text { residents; } 1 \text { session } \\
\text { with prototype version } 1\end{array}$ \\
\hline 3 & 1 & $\begin{array}{l}1 \text { staff, } 1 \text { volunteer, } 4 \text { residents; } 1 \text { session } \\
\text { with version } 1 \text { and } 2 \text { (river tour) }\end{array}$ \\
\hline 4 & 1 & $\begin{array}{l}3 \text { staff and } 5 \text { residents; } 1 \text { session with } \\
\text { version } 2 \text { (river and park tour) }\end{array}$ \\
\hline 5 & 1 & 2 managers, 3 staff (further discussion) \\
\hline 6 & 1 & 4 staff (focus group) \\
\hline 7 & 1 & 3 staff (focus group) \\
\hline 8 & 2 & $\begin{array}{l}3 \text { staff and } 4 \text { residents; } 3 \text { sessions with } \\
\text { version } 3\end{array}$ \\
\hline 9 & 2 & $\begin{array}{l}3 \text { staff and } 5 \text { residents; } 2 \text { sessions with } \\
\text { version } 3\end{array}$ \\
\hline
\end{tabular}

Table 1: A summary of the visits with the care homes.

\section{The care homes}

Two care homes based in South East England participated in the study. The first one was a large care facility housing more than 100 residents. The second was a smaller care home with around 50 residents. The residents had a variety of declines in their cognitive and physical abilities. All of them had some forms of dementia. The residents were aged between 80 and 101 years old. To promote the well-being and life engagement of the resident, both care homes regularly organise activities, which include gardening activities and dancing. Occasional outings are also organised in which participants are taken to the beach, the bar or go shopping. Most of these activities require close supervision of the carers. This is especially true for outdoor activities, which according to the carers, typically involve one carer looking after no more than 3 residents.

\section{Virtual world prototypes}

Three versions of VW prototypes were developed in this study using Unity3 $\mathrm{D}^{1}$. A main feature of the design we specified early on was to make interaction as simple as possible to enable a group of users to simultaneously interact with the VW. A number of studies have emphasised how older people prefer and benefit from interactive applications (in particular, video games) that could be enjoyed in a social setting [21]. Moving away from the traditional mouse and keyboard interface, we focused on gesture and touch-based interfaces. The Microsoft Kinect sensor $^{2}$ was used to detect the user's gestures and motions and the $\mathrm{ZDK}^{3}$ (Zigfu development Kit) was used as a middleware to facilitate the development of the gesture controlled system through Unity3D. A projector was used to display the VW. Initially, we aimed to utilize the capacity of the Kinect in detecting full body interactions. However from the observation sessions, we found that the residents became physically exhausted. In addition, residents in wheelchairs were unable to participate. Hence, in the later designs, the Kinect was set to seated mode and only movements from the user's arms were used.

\section{Version 1: Reminiscence Room Prototype}
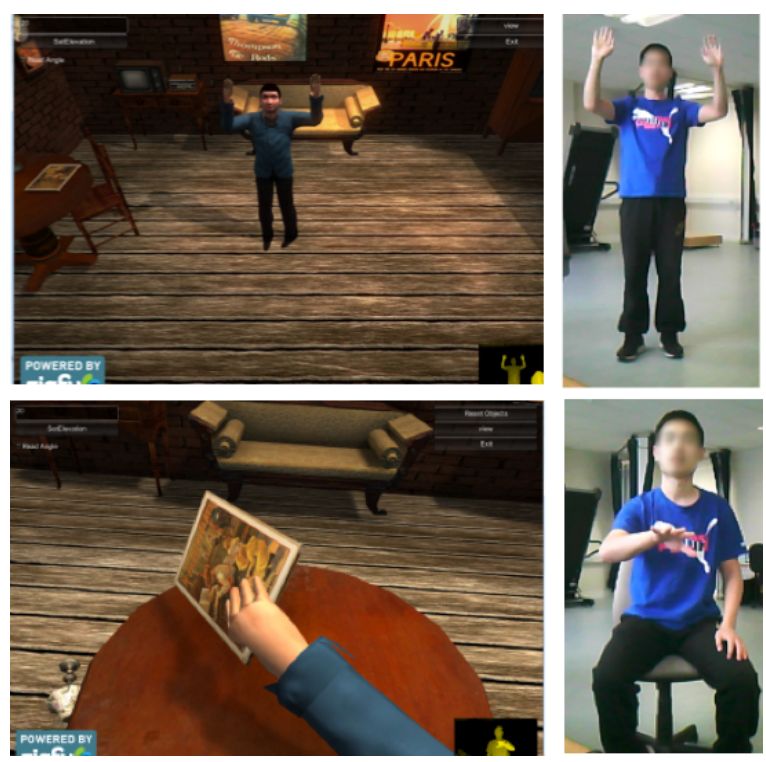

Figure 1: Virtual room prototypes. The top images depict the walking mode and the bottom images depict the seated mode. The images on the left depict what is shown in the VW and the images on the right depict the user (not actual participant).

The first prototype presented the user with an avatar placed in a virtual room with objects from the past (old posters, magazines, TVs, books). A radio was also included in the virtual room playing music of that period. Two modes of interaction were available. In the first mode (walking

\footnotetext{
${ }^{1}$ http://unity3d.com/

${ }^{2} \mathrm{http} / / /$ www.microsoft.com/en-us/kinectforwindows/

${ }^{3} \mathrm{http}: / /$ zigfu.com/en/zdk/unity3d/
} 
mode), Kinect was used to map the users interaction to the avatars. More than 10 joints (e.g. Head, Torso, Waist, etc.) were detected and their movements mapped onto the avatar (see Figure 1). In the second mode (seated mode), the avatar was seated in front of a table with virtual objects (a book, a magazine, a radio and a lamp) placed in front of the user. In this mode, Kinect only detected the movements of the upper body (arms and upper torso) and the user would remain seated in the physical world. The user could pick up items on the table by moving their hands to touch the object. Each mode had a first and third person view.

\section{Version 2: Virtual Tour Prototype}
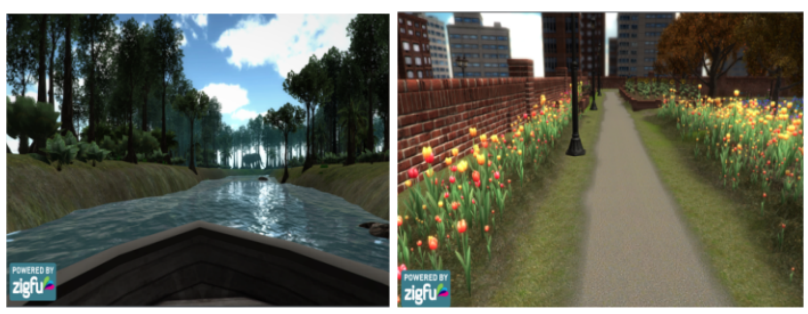

Figure 2: The river tour (left) and park tour (right).

The second version of the prototype was created based on the idea of users being taken along for a virtual tour through a pre-determined path. Two virtual worlds were created: the river tour and the park tour. In the river tour, the participant was taken through a virtual river trip. The environment was created to resemble a tropical forest, with vegetation, plants and animated animals (such as elephants, rhinoceros, etc.). The user would tour around the river by doing a "rowing" motion with their arms, which would propel the boat forward along the path. The park tour was created to depict the experience of walking through a park. Users would move their arms to simulate a "jogging" motion to move around the virtual park. In this prototype, various animals were programmed to respond to the user as they got close. For instance, rabbits would hop away from the user and humanoid characters would wave at the user as they "walked" closer. A screenshot is shown in Figure 2.

\section{Version 3: Gardening Prototype}

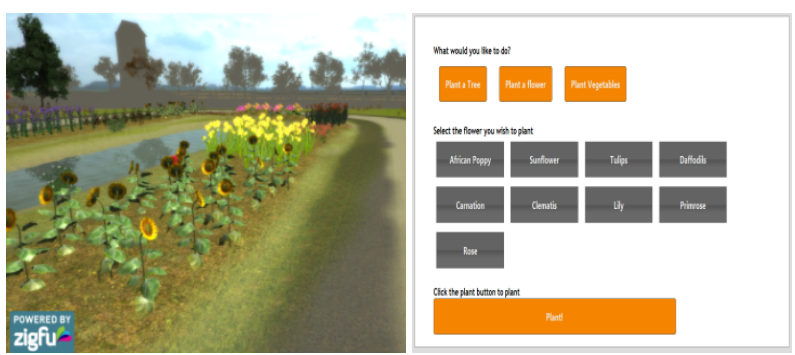

Figure 3: A screenshot of the virtual garden prototype (left) and the interface of the tablet controller (Right)

In this prototype, the participant would work together with the caregivers to design a virtual garden. 20 objects were available for selection including nine types of flowers, four types of trees and seven types of vegetables. An Androidbased tablet computer was used to allow the caregiver/residents to select the vegetation to plant in the virtual garden (see Figure 3). The participant would "walk" to the empty plot using Kinect in a similar manner as prototype version 2 . As they came close to an empty lot, a text would be displayed on the screen, asking the participant to select the plant. The user would then select the plant with the tablet computer and the plant would slowly pop up from the ground, followed by text feedback with a cheering sound effect as well as visual effects.

\begin{tabular}{|l|l|}
\hline $\begin{array}{l}\text { Version } \\
\text { change }\end{array}$ & Design choices and changes in each iteration \\
\hline $\begin{array}{l}\text { 1(virtual } \\
\text { room) }\end{array}$ & $\begin{array}{l}\text { Gesture-base technology instead of the } \\
\text { traditional mouse and keyboard was adopted }\end{array}$ \\
\hline $\begin{array}{l}\text { 1(virtual } \\
\text { room) -> } \\
\text { 2(river } \\
\text { tour) }\end{array}$ & $\begin{array}{l}\text { Interaction in version 1 was too complex, To } \\
\text { reduce the complexity, the design approach for } \\
\text { passive interaction is adopted. To include } \\
\text { residents in wheelchairs, the prototype utilized } \\
\text { interaction only from arm movements. Ambient } \\
\text { sound effects (river flowing, bird sounds) were } \\
\text { added to enhance engagement. This replaced } \\
\text { the music from the radio in version 1 which } \\
\text { drew their attention away from the VW. }\end{array}$ \\
\hline $\begin{array}{l}\text { 2(river } \\
\text { tour) }->\end{array}$ & $\begin{array}{l}\text { As residents had trouble relating to unfamiliar } \\
\text { content (animals and plants in the river tour } \\
\text { etc.), this version focused on more common } \\
\text { tour) } \\
\text { objects (e.g. flower and animals seen more in } \\
\text { which mimics a "wonderland". This was aimed } \\
\text { to better retain the attention of residents. }\end{array}$ \\
\hline $\begin{array}{l}\text { 2(park } \\
\text { tour)-> 3 } \\
\text { garden) }\end{array}$ & $\begin{array}{l}\text { This prototype was designed to provide social } \\
\text { interaction that allowed the resident and the } \\
\text { care staff to design the garden together }\end{array}$ \\
\hline
\end{tabular}

Table 2: A summary of prototype iterations

\section{FINDINGS}

The findings are organised and presented to reflect three key aspects of the use of VW to support life engagement for people with dementia. The first theme relates to how the experiences as a result of their interaction with the VW stimulate past memories, helping to augment a sense of self. The second theme outlines the approaches employed to draw users' attention and create ludic experiences, a challenging task considering the cognitive impairments faced by people with dementia. The final theme involves addressing how interaction in VWs could be facilitated. Conventionally, many tasks required to interact with the VW (such as navigation, manipulation, etc.) are difficult to carry out especially for people with cognitive disabilities. We discussed in depth how we attempted to overcome these issues. Since the main form of data were 
observation notes, passages were quoted from our notes to provide illustration to the findings.

\section{Augmenting the sense of self}

The declines in cognition and memory among people with dementia have been argued to result in a "loss of self" [10]. The experiences and memories invoked by the VW could help augment the sense of self for older people with dementia. VWs allow the residents to temporarily step outside of their closed physical environment of long-term care facilities and transport them to a (albeit virtual) world of reminiscence. When the residents are institutionalised, their life is disrupted, the continuity broken [25]. VWs could provide a "memory sanctuary" to maintain this continuity of self. Three main aspects of reminiscence were observed in the study: i) reminiscence from the sense of place, ii) virtual object-based reminiscence, iii) reminiscence from the motion (gesture-based interactions).

\section{Augmenting the sense of self through places}

A quintessential feature of VW is its ability to simulate a variety of places; places no longer accessible to the residents in long-term care (these could be as simple as their own garden or kitchen, or holiday destinations) or places which have ceased to exist physically, but still linger in their memory (such as a historic street destroyed in the war). Place-based reminiscence is a particularly noteworthy example which was reflected in our observation. The ability to re-experience past places has been argued to help in the recovery of self [9]. An interesting observation from this study was how some interactions of the residents were in essence an attempt to connect the virtual place to self, actively creating meaning through conversation and interaction. In line with previous studies looking into selfhood and (physical) places [38], we observed how engaging with the virtual garden not only prompted the residents to tell stories about their own garden, but also personal stories about people and experiences related to their past. VWs not only allowed the resident to remember particular objects (flowers, trees, buildings etc.), but also triggered the overall feeling of "being in a garden."

Note: During the virtual garden design activity with the caregivers, the resident began by talking about plants he grew in his own garden when he was younger and gave detailed descriptions about his garden. He told us about the rail track [note that there was no rail track in our virtual garden] next to his garden and then moved on to telling stories about his family rail trips to Europe.

As previous studies have argued that meaningful places could play a role in the maintenance and construction of one's identity [34], the example here points to the potential of virtual places in augmenting the resident's sense of self. One limitation for those living with cognitive and physical disabilities is that much of their environment is confined to within the space of the care home [13]. Although the care homes we visited organise occasional trips, it might not be logistically feasible to frequently organise outdoor visits to certain places and for all the residents. Although photographs of past places could also invoke this type of reminiscence, a full interactive $3 \mathrm{D}$ environment (which allows one to see trees waving in the wind and hear the ambient sounds of birds singing and the wind blowing) could provide a platform to immerse the users and increase the perception of them being in the place.

\section{Augmenting the sense of self through the virtual objects}

Like most care homes, the two care homes we visited were filled with objects of the past: old radio, old furniture and dinnerware, etc. Perhaps the most common form of reminiscence activity practiced in care homes is based on objects and the two care homes actively engage their residents in such activity. Researchers have argued that physical day-to-day objects from everyday life have as much value in storing memories as photographs, helping to remind us of past experience and achievements [31]. Therefore, it is not surprisingly that in many occasions, the virtual objects in VW seemed to invoke reminiscence among the residents, prompting them to express a sense of self and remember stories from their past. Such instances were commonly observed (such instances were observed in 5 observation sessions.):

Note: In the virtual garden prototype, the resident mentioned how she wanted to grow a lily and then explained to us how she could never have one in her own garden as she is allergic to it.

VWs containing objects of personal relevance to the residents were much more successful in stimulating conversation and life engagement. In the virtual river tour prototype for instance, the discussion did not go beyond simply pointing out the names of the animals as for most residents, the objects had no relevance to their past (apart from one resident who used to live in South Africa). The virtual park and virtual garden prototypes contained objects commonly seen by the residents in their daily life and were more successful in engaging the residents.

Note: Since women live longer than men, it is not surprisingly that there are more female and male residents in the care homes. Whilst most female residents greatly enjoyed the garden prototype (7 residents) and the park prototype (3 out of the 4 who participated), two of the male residents who used the park prototype were completely switched off. The caregiver later told us about the fascination of one male resident in cars and tractors.

\section{Augmenting the sense of self through motion}

One unexpected observation in this study was how motions provided an opportunity for the augmentation of selfhood. Although the decision to use Kinect was originally made mainly to address the issue of "ease of use", mapping user motion to the avatars (in the reminiscence room prototype) prompted the residents to try to recreate past experiences 
through movements. A particularly memorable example was found in the following case.

Note: During the testing of the virtual room prototype, one participant (who was familiar with boxing) took a boxing stance and tried to make the avatar engage in boxing. He enjoyed watching the on screen avatar mimicking his movement.

Despite the virtual room offering no artefacts or stimulus related to boxing (the room contained only household objects from the past and no boxing gloves or other related apparatus), the resident devised and acted out an activity based on something that was more personally relevant to him. This aspect of interaction opens a new and unique way in which digital technology can engage with older people in augmenting their sense of self and reminiscence. Perhaps it is not only the visual and audio stimulus but also motions which could help older people recall their past memories.

Research has suggested that the ways in which we think is an extension of our existence as embodied minds [5]. The way we think is driven by our physical motions, which in turn drive the way that we think. For instance, a piano player is not normally able to write down the keys that they hit in a piece of music they know, but if they can sit at the piano and use their "muscle memory", they will remember the order of the keys. This is because their memory isn't a visual memory but is embodied within finger movements. Tapping into this fundamental human ability could enable people with dementia engage their memory more fully. Indeed, one technique used in reminiscence encourages older people to act out their past experiences, such as asking them to waiter or use props such as a washboard for someone who has worked in a cafe [20]. In the same vein, gesture sensors such as Kinect could be used to facilitate such actions and relate them to the virtual environment.

The suspension of disbelief: slipping into alternate reality For VW to be effective, users should be able to suspend their disbelief and maintain the illusion that the alternative place simulated by the VW is believable. During the observations, we were pleasantly surprised by the ease in which the people with dementia suspended their disbelief and expressed a strong sense of "being inside" the VW:

Note: The activity coordinator asked what the resident had thought [about the garden]. She answered that it was wonderful and it looked like she was in a real garden.

Note: After the resident had finished planting the whole garden, she asked the activity coordinators where this garden was. She assumed that this garden was one existing in reality and this was a real-time visual display of an actual garden.

Some observations highlighted not only the perception of "being present" but also the feeling of actually carrying out the activity.
Note: In the river prototype, the resident grinned as she was moving her hands to row the boat enthusiastically, one made a comment of "I am rowing the boat!"

Overall, almost all residents were able to see the projected screen as a place they were situated in and perceive themselves as actually performing the activity. This was a surprising observation. The concept of presence has always been one of the key research topics in virtual world/reality studies. Although generally most users were able to suspend disbelief and "pretend" they were inside the virtual world, in one case, the resident mistook the virtual environment as being the "real world". Indeed, studies looking into the use of virtual reality and dementia found that despite having cognitive disabilities, users with dementia were able to perceive a sense of presence [16]. This would certainly calls for further studies investigating the sense of presence among people with dementia.

\section{Designing sustained ludic experiences}

A key challenge to design VW for people with dementia is to find ways to engage and entertain them. Cognitive impairments caused by dementia result in impairment to attention [29], making it difficult to design activities which sustian their attention for prolonged periods. In this section, we outline the approach we adopted to create and maintain ludic experiences for the residents.

\section{The construction of "wonderland" effects}

At first, the audio-visual design aspects of the VW did not seem to be an important factor to us. However after two sessions, we learnt the importance of this design issue. Our initial assumption was that VWs should look as realistic as possible, given the constraint of computing power and labour intensity. Our early prototypes attempted to depict the virtual environment as it is in the "physical world." It quickly transpired that realism alone is insufficient. In fact, it might even be less engaging for the residents. After a focus group session with the care staff, one method we devised and found particularly effective was to present the environment in a manner which mimics "a wonderland" from the children's stories. We created the virtual park and the virtual gardening prototypes to incorporate this idea. Designing for this effect involved modifications such as:

- Objects with bright and contrasting colours were used and image filters applied to further highlight and create a "glowing" effect on the objects.

- When providing feedback to users (such as when growing a plant), stimulating visual and sound effects were used. A text animation of "well done" whizzed in from the top of the screen, followed by clapping and cheering sounds.

- Colourful particle effects were used. Brightly coloured particles were programmed to spring from the ground as the plant was growing and firework particles were used to further draw the user's attention after the "well done" text animation was played (see Figure 4). 
The main purpose of this design approach was to create an over-the-top experience. Use of bright colours, particles and sound effects proved successful to help draw in and sustain the attention of the residents:

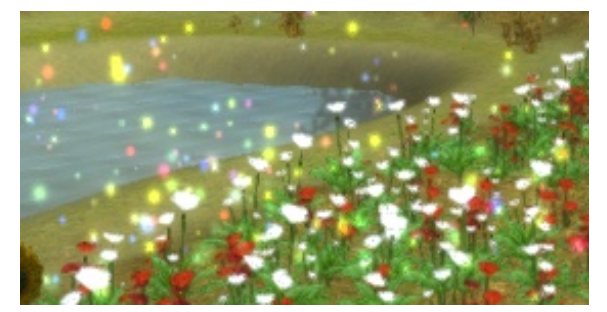

Figure 4: A screenshot of the particle affects and bright growing colours used to create the "wonderland" feeling

Note: In the virtual park tour prototype, the bright flowers drew the attention of the residents, prompting them to try to figure out what type of flowers they were. In addition, some of the residents pointed to the screen and asked the others to look at the flower.

In addition to drawing in the attention of residents, contrasting and bright colours may also improve usability for older people in general [12]. Using bright and contrasting colours make the objects stand out and serve to draw in the viewer's attention [11]. This is similar to the designs of toys for young children which have used similar techniques to attract their attention [24].

We also made interesting observations regarding the use of sound and music. In the reminiscence room prototype, old music was initially included with the hope to engage the residents with the VW. We indeed observed the residents getting more lively and energetic. Some of them started dancing to the music. They were however engaged in the music and less so with the virtual room. Instantly, they were drawn out of the virtual environment, into the world of music. The use of ambient sounds (e.g. river flowing, birds chirping, etc.) however, seemed to have increased their engagement with the VW. For people with dementia in long-term care, their world is largely constrained within the care home environment. What for many of us are day-today activities, such as walking down a street on our own, taking a stroll in a park, gardening, are for some of them "extraordinary" things they can no longer do due to physical and cognitive decline. Often, these are fragment of memories remained in their mind. Thus, we believe that VWs provide a means for them to reconnect their experience to the "day-to-day" yet "extraordinary" worlds.

\section{Inducing positivity}

Engaging with virtual activities could also help induce a feeling of positivity. This point was frequently raised during the focus group discussions with the care staff. They emphasised that one beneficial aspect of VWs in care was to help restore the mood of the residents to a more positive state. It is because depression and rapid changes in mood and emotion are common problems associated with dementia [37]. An example is shown in the following case:

Note: Although the resident started his story with his garden and his happy time with his parents, the story took a turn when he begun talking about the death of his father after the war, and how this affected his life. He became teary and the care staff promptly drew him back to the virtual garden and stopped the negative emotion from escalating

Drawing his attention back to garden creation activity helped the resident to deal with his negative experiences in a more positive way.

\section{User Interactions}

We observed that rarely was meaningful interaction confined between the VW and the resident. Often, the interactions between the residents with each other and with the carers played a crucial role in forming their experience. Therefore, VW design needs to weave together these different types of interactions meaningfully to support the residents. In this section, we discuss our reflections with each type of user interaction.

\section{Designing for passive interactivity}

We learnt that a key challenge in designing interaction for people with dementia was in finding a balance between the complexity of the virtual activity and the simplicity of the user interaction. Increasing the level of user interaction provides more rooms for potential engagement, but could also increase the level of complexity and thus alienate less capable residents. An example could be observed with the reminiscence room prototype. Giving the participants full freedom to move around in the $3 \mathrm{D}$ room provided more avenues for interaction, but required a substantial level of effort to interact with the system. This often made residents with more severe cognitive disabilities confused:

Note: One participant was not able to identify from the third person view that they were controlling their avatar. As the camera in this prototype was linked to the avatar's movements, participants were confused and frightened of the lack of control they felt as they perceived the wall to move on its own.

Despite this, merely reducing the level of interaction could severely limit the activities available and result in a less interesting prototype. To solve this problem, we focused on creating experiences of "passive interactivity". Creating experiences of "passive interactivity" was aimed to increase the level of interactivity without increasing complexity to a large degree. Most commercial 3D VWs adopt a form of "active interaction", using the avatar as the base for interaction. For instance, if the user wants to interact with an object, they would navigate their avatar to the vicinity of the object to interact with it. This form of active interaction would be challenging with people with dementia [30]. 
Drawing from the lessons in early sessions, we revised our prototypes by including more "passive interactive" experiences. We found more successes when the objects were designed to "come" to the participants and "respond" to their interactions instead of needing the user to "go" to the objects. Previous technologies designed for dementia have adopted similar forms of interaction. For instance, in the design of an interactive photostroller, researchers devised a "tuner" to give participants the ability to select the category of the photos (a sense of control), while the photos would be showed in an automatic "drifting" motion (the pictures would in essence, be "presented" automatically to the users [17]). To a certain extent, we were creating an experience similar to a ride in an amusement park. The objects of interest were designed to interact with the participants as they drew closer. As Kinect ensured that participants were able to maintain a sense of control, participants were able to "interact" with the environment in a state of relative passivity.

To increase the range of interaction and activities for residents who had more severe cognitive disabilities, "passive interactivity" in the form of mediated interaction was achieved by including carers to help in the decision process. The virtual garden prototype for instance was designed around the idea of a collaborative activity between the carer and the resident. The carers helped older users make the decision of which plant to use, giving participants a level of control over the decision process whilst allowing residents to passively observe the results of their interactions. In a sense, the carers played the role of "game orchestrator", constructing narratives and helping direct and guide the experience of the residents [19].

\section{The role of the carer}

In our early prototypes (the reminiscence room and river tour prototypes), our design emphasis was focusing on designing the VWs to work with the residents with minimal support from care staff. This approached yielded limited success. We observed that some residents were able to interact with the prototype without help (rowing the boat in the river tour, some were able to interact with the avatar etc.), and they were able to recognise various objects and expressed interest in them. However it often required further prompting from the carers to stimulate more meaningful activities. For instance, the carers played a key role in stimulating storytelling, a core aspect in reminiscence activities. For residents with more severe levels of cognitive declines, carers also played a role in directing the attention of the residents. Facilitating a more meaningful interaction for these users often required additional guidance from staff the residents were familiar with and trusted. The virtual garden prototype in particular was designed around this idea, as a joint activity between the carers and residents. In this respect, we believe that VWs could be useful to foster relationship between care staff and the resident beyond basic-care interaction (such as feeding, washing, etc.). Engaging care staff and residents in playful social activities together could help enhance expressive relationships and trust.

\section{Interaction between the residents}

A key feature of VWs is the ability of the users interacting with each other. We were keen to explore this social aspect in the context of dementia care. Although the prototypes were helpful in supporting expressive and personal interactions between residents and care staff, we observed only few instances where meaningful social interactions occurred between the residents through the VW. In the focus group with the care staff, we explored this issue:

Note: the care staff thought that the residents might not benefit hugely from a group activity around virtual world in the virtual garden activity. He believed that it is because the residents need to cognitively process the information (remembering the flowers options, linking flower name with what it looks like, looking at the screen, and the tablet computer). In addition, in a group, they will have to process social information as well: deciding what to plant together. Some might be dominant, and argue, and some might just sit back. Cognitive and social skills will be competing for their mental capacity.

In hindsight, it was perhaps not surprising that the main meaningful social interactions were between the residents who were passively observing the activity and those who were using the prototype. For instance, in the virtual park and river tour prototypes, some residents observing the activity had as much fun being a passive observer as those who were using the prototype. In one case, a resident decided to join in only after having seen someone use the prototype. The VW setup in the care home (i.e. using a projector as display and Kinect as motion controller) in particular opened opportunities for such forms of interaction, as they allowed multiple residents to observe and interact with the system simultaneously. Some residents preferred to be a "passenger", passively observing the VW and talking to residents interacting with the prototype.

\section{DISCUSSION}

Through the study, we have explored in depth how VW technology was used by people with dementia and their caregivers in long-term care. Testing and revising a number of prototypes also gave insights related to design issues. Each prototype had different benefits for difference group of users and it could not be said that one is better than the other. We are also not advocating replacing physical activities with only virtual activities. Instead, we believe that VW can provide interactive experiences to promote a continuing selfhood which may have been lost due to dementia and/or moving to long-term care facilities. It can also provide stimulation and engagement to promote a feel good factor. Negative memories could be mitigated by playful design. VW could also be a "place" that allows staff and residents to foster personal relationship and trust, which 
may improve care. Although it appeared from the observation that VWs worked with many residents to a certain extent, there were incidents where they did not work well. We highlight some problems we encountered, which could direct future design and research work:

- Excessive physical motion: for some residents, continuous use of Kinect caused fatigue. In addition, many residents were confined to wheelchairs and this did not permit them to use the virtual room prototype (version 1). Although later versions utilised only hand movements, those who have difficulty moving their arms (such as those relying on Zimmer frames for movements) could still find their experience limited.

- Personally, irrelevant places, objects and activities: The virtual garden and park prototypes were especially successful among female residents but less so with the male residents who preferred other activities such as driving or sports. This underlines a key limitation of the wider use of VW in care home as creating different virtual environment is rather costly at the moment.

- In some cases, negative memories were triggered from the VW. This required the care staff to redirect their attention back to the positive aspect of the activity.

- Although some care staff was very keen to try the technology, others were less enthusiastic as the technology was perceived as adding extra workload to their already busy schedule.

- Most of the people with dementia were able to interact with the prototypes with relative ease. However, we observed a few cases (those with more severe cognitive declines) where the residents were unable to perform the simple tasks on touch screen or using gesture. In these cases, their visual audio capabilities have been significantly reduced and often the caregivers would guide them by physically touching them (especially their shoulders and hands) to get their attention.

Given these limitations and challenges, we envision at least two immediate ways future research could focus on. The first would be the use of intelligent avatars as social agents to facilitate these virtual activities, such as guiding the users through the VW and offering prompts to stimulate further conversation/storytelling. One key limitation of the current prototypes was the extensive involvement required from the care home staff. With the social agents, the role of the caregivers would be to oversee these virtual activities and intervene when unexpected problems arise. Prior studies have shown that such agents have been used successfully to converse or give instructions to older users [13]. The second research direction involves the use of tangible user interfaces, especially for those with more severe dementia. We often observed how important tactile interaction was in the interaction with VW. For instance, in the virtual gardening prototype, there was a tendency for the care staff to give the tablet to the residents, and physically guide them to click and select the flowers by touching their hands. These help them feel more empowered carrying out the activity. Therefore, future work could address this by designing a tangible/physical interface such as using replicas of the plants instead of a touch screen interface.

In summary, we hope that the outcomes from the study offer some insights into the design and use of VW technology for dementia care.

\section{ACKNOWLEDGMENT}

The project is funded by EPSRC (EP/J010766/1).

\section{REFERENCES}

1. Alzheimer's association. 2013 Alzheimer's disease facts and figures. Alzheimer's association (2013).

2. Bharucha, A. J., Anand, V., Forlizzi, J., \& Dew, M. Intelligent assistive technology applications to dementia care: current capabilities, limitations, and future challenges. The American journal of geriatric psychiatry, 17, 2 (2009), 88-104.

3. Bickmore, T. W., Caruso, L., Clough-Gorr, K., \& Heeren, T. 'It's just like you talk to a friend' relational agents for older adults. Interacting with Computers, 17,6 (2005), 711-735.

4. Boers, N. M., Chodos, D., Huang, J., Gburzynski, P., Nikolaidis, I., \& Stroulia, E.. The Smart Condo:

Visualizing independent living environments in a virtual world. Pervasive Computing Technologies for Healthcare, 2009. PervasiveHealth 2009. IEEE (2009), 1-8.

5. Borghi, A. M., \& Cimatti, F. Embodied cognition and beyond: Acting and sensing the body. Neuropsychologia, 48, 3 (2010), 763-773.

6. Botella, C., Etchemendy, E., Cast, D., Baños, R. M., García-Palacios, A., Quero, S., et al. An e-Health System for the Elderly (Butler Project): A Pilot Study on Acceptance and Satisfaction. CyberPsychology \& Behavior 12,3 (2009), 255-262.

7. Bózzola, F. C., Gorelick, P. B., \& Freels, S. Personality changes in Alzheimer's disease. Archives of Neurology, 49,5 (1992), 486-491.

8. Caldwell, P. Finding You Finding Me: Using Intensive Interaction To Get In Touch With People Whose Severe Learning Disabilities Are Combined With Autistic Spectrum Disorder. Jessica Kingsley Pub : London (2006).

9. Chaudhury, H. Journey Back Home Recollecting Past Places by People with Dementia. Journal of Housing For the Elderly 16,1-2 (2008), 85-106.

10. Cohen, D., \& Eisdorfer, C. the loss of self: A family resource for the care of Alzheimer's disease and related disorders. . Norton \& Company, (2001).

11. Creusen, M. E., \& Schoormans, J. P. The different roles of product appearance in consumer choice. J. of product innovation management 22,1(2005), 63-81. 
12. Czaja, S. J., \& Lee, C. C. Information technology and older adults. In A. Sears, \& J. A. Jacko, HCI Handbook: Fundamentals, Evolving Technologies and Emerging Applications. New York: Lawrence Elbaum Associates. 2007, 777-792.

13. Dupuis, S. L., B. J., \& Wiersma, E. Creating open environments in long-term care settings: an examination of influencing factors. Therapeutic Recreation Journal, 39,4 (2005), 277-298.

14. Edvardsson, D, Edvardsson, B \& Sandman, PO Personcentred care of people with severe Alzheimer's disease: current status and ways forward. The Lancet Neurology. 7, 4 (2008), 362-367

15. Ephraim, G. A brief introduction to augmented mothering. Playtrack pamphlet, Harpebury Hospital School:Radlet Herts, (1986)

16. Flynn, D., van Schaik, P., Blackman, T., Femcott, C., Hobbs, B., \& Calderon, C. Developing a virtual realitybased methodology for people with dementia: a feasibility study. CyberPsychology \& Behavior 6, 6 (2003), 591-611.

17. Gaver, W., Boucher, A., Bowers, J., Blythe, M., Jarvis, N., Cameron, D., et al. The photostroller: supporting diverse care home residents in engaging with the world. Chi '11 Proceedings of the SIGCHI Conference on Human Factors in Computing Systems. ACM (2011), 1757-1766.

18. Gowans, G., Campbell, J., Alm, N., Dye, R., Astell, A., \& Ellis, M. Designing a multimedia conversation aid for reminiscence therapy in dementia care environments. CHI '04 Extended Abstracts on Human Factors in Computing Systems. ACM (2004), 825-836.

19. Graham, T. N., Schumann, I., Patel, M., Bellay, Q., \& Dachselt, R. Villains, architects and micro-managers: what tabula rasa teaches us about game orchestration. Proceedings of the SIGCHI Conference on Human Factors in Computing Systems. ACM (2013), 705-714.

20. Head, D. M., Portnoy, S., \& Woods, R. T. The impact of reminiscence groups in two different settings. International Journal of Geriatric Psychiatry 5,5 (1990), 295-302.

21. Ijsselsteijn, W., Nap, H. H., de Kort, Y., \& Poels, K.. Digital game design for elderly users. Future Play '07, Proceedings of the 2007 conference on Future Play. $\operatorname{ACM}(2007), 17-22$.

22. Jaffe, D. J. Problematizing meaning. In Qualitative methods in aging research. Thousand Oaks, CA: Sage Publications, 1994.

23. Kuwahara, N., Abe, S., Yasuda, K., \& Kuwabara, K. Networked reminiscence therapy for individuals with dementia by using photo and video sharing.

Proceedings of the 8th international ACM SIGACCESS conference on Computers and accessibility. ACM (2006), 125-132.

24. Light, J. C., Drager, K. D., \& Nemser, J. G. Enhancing the Appeal of AAC Technologies for Young Children:
Lessons from the Toy Manufacturers. Augmentative and Alternative Communication 20,3(2004), 137-149.

25. Lin, Y. C., Dai, Y. T., \& Hwang, S. L. The Effect of Reminiscence on the Elderly Population: A systematic Review." Public Health Nursing. 20,4(2003), 297-306.

26. Luengo-Fernandez, R., Leal, J., \& Gray, A. Dementia 2010: The economic burden of dementia and associated research funding in the United Kingdom. Cambridge: Alzheimer's Research Trust, 2010.

27. Marshall, M. The challenge of looking after people with dementia: Professional carers need higher expectations and better training and support. BMJ: British Medical Journal 323, 7310 (2001), 410-411

28. Mayeux, R. Early Alzheimer's Disease. New England Journal of Medicine, 362 (2010), 2194-2201.

29. McGuinness, B., Barrett, S. L., Craig, D., Lawson, J., \& Passmore, P. A. Attention deficits in Alzheimer's disease and vascular dementia. Journal of Neurology, Neurosurgery and Psychiatry, 81,2 (2010), 157-159.

30. Moffat, S. D., Zonderman, A. B., \& Resnick, S. M. Age differences in spatial memory in a virtual environment navigation task. . Neurobiology of aging, 22,5 (2001), 787-796.

31. Petrelli, D., \& Whittaker, S. Family memories in the home: contrasting physical and digital mementos. Personal and Ubiquitous Computing 14,2(2010), 153169.

32. Riley, P., Alm, N., \& Newell, A. An interactive tool to promote musical creativity in people with dementia. Computers in Human Behavior 25,3 (2009), 599-608.

33. Rogers, W. A. Human factors, applied cognition, and aging. (2000).

34. Twigger-Ross, C. L., \& Uzzell, D. L. Place and identity processes. Journal of Environmental Psychology 16,3 (1996), 205-220.

35. Wallace, J., Wright, P. C., McCarthy, J., Green, D. P., Thomas, J., \& Olivier, P. A design-led inquiry into personhood in dementia. CHI '13 Proceedings of the SIGCHI Conference on Human Factors in Computing Systems . ACM (2013), 2617-2626.

36. Wang, J. J. Group reminiscence therapy for cognitive and affective function of demented elderly in Taiwan. International Journal of Geriatric Psychiatry 22,12 (2007), 1235-1240.

37. Whalley, L. Early Onset Dementia. In S. Hunter, Dementia: Challenges and new directions. Jessica Kingsley Publishers. 1997, 71-78.

38. Williams, A. Changing geographies of care: employing the concept of therapeutic landscapes as a framework in examining home space. Social Science \& Medicine, 55,1 (2002), 141-154.

39. Woods, B., Spector, A. E., Jones, C. A., Orrell, M., \& Davies, S. P. Reminiscence therapy for dementia. Cochrane Database Syst Rev 2 (2005). 